\title{
A PROSPECTIVE AND OBSERVATIONAL SINGLE INSTITUTION EXPERIENCE IN
}

\section{LAPAROSCOPIC CHOLECYSTECTOMY:}

The De La Salle University Medical Center Experience

Michael M. Lawenko, Arvin Ilagan, Abigail Dumlao, Gerry Gonzales, Jesus Versoza

Department of Surgery, De La Salle University Medical Center Dasmariñas City, Cavite 


\section{ABSTRACT}

\section{$\underline{B A C K G R O U N D}$}

Laparoscopic Cholecystectomy (LC) is now the gold standard for surgical management of cholelithiasis around the world especially in developed countries, with the advantages of returning to work early, less postoperative pain, shorter hospital stay and better cosmesis. Here in the Philippines, LC has just started to pick its pace; surgeons are becoming more adept in the technique and patients have a better option with regards to the procedure to undergo.

The aim of this study is to analyze our institution's experience in laparoscopic cholecystectomy by evaluating the operative time, patients' pain score post-operatively, hospital stay, intra-operative and post-operative complications (bleeding, bowel injury and bile duct injury) conversion rate and length of post op stay.

\section{$\underline{\text { METHODS }}$}

A prospective analysis was performed on data collected during a 16-month period (January 2010 to May 2011) from 127 patients who underwent laparoscopic cholecystectomy. All of the surgeries were performed by consultants.

\section{RESULTS}

The mean age was 44.7 (17-78) with whom $65.5 \%$ were females. Fifteen patients (13.6\%) were operated in the acute setting. Three patients $(2.7 \%)$ warranted an intraoperative cholangiogram while $5(4.5 \%)$ underwent an Endoscopic Retrograde Cholangiopancreatography immediately prior to LC. The mean operating time was $89(35-335 \mathrm{SD} \pm 41.75)$ minutes. One patient had cystic duct leak which was managed with a drain and post LC ERCP. Difficulty in dissection was experienced in one case hence conversion to open cholecystectomy occurred $(0.9 \%)$. Postoperatively, $101(91.8 \%)$ received $0.5 \%$ Bupivacaine subcutaneously through the incision 
sites. Average VAS score was noted to be 3.05, 2.60, 2.20 at 6, 12 and 24 hours respectively. The mean post operative stay after the procedure was $36.22(10-189 \mathrm{SD} \pm 25.01)$ hours. No wound infection nor early incisional hernia was noted after 1 week of follow up.

\section{CONCLUSION}

With the early series of cases, it can be inferred that laparoscopic cholecystectomy is feasible and is performed safely in our institution.

KEYWORDS: Laparoscopy, Acute Cholecystitis, Chronic Calculous Cholecystitis, Laparoscopic Cholecystectomy, institutional experience, intraoperative complications, conversion. 


\section{INTRODUCTION}

Laparoscopic cholecystectomy (LC) has replaced open cholecystectomy in the treatment of patients with symptomatic gallstone disease. ${ }^{1}$ It has become the "gold standard" in the surgical management of cholecystolithiasis. ${ }^{2,3,4}$ Advantages of laparoscopic cholecystectomy include early return of bowel motility, early return to work, lesser post-operative pain, shorter hospital stay and better cosmetic results. ${ }^{5}$ Several studies have documented use of laparoscopy even in an acutely inflamed gallbladder and in emergency settings. 4, 6,7

The use of laparoscopy in cholecystectomy in our institution formally started upon acquisition of our own laparoscopy machine in January 2010. Since then, a continous increase in laparoscopic cholecystectomies are being done, under the supervision of two of our graduates who underwent training in Minimally Invasive Surgery and Hepatobiliary overseas. The aim of this study is to describe the institution's experience prospectively as well as to document the fesibility and safety of laparoscopy in cholecystectomy.

\section{METHODOLOGY}

\section{$\underline{\text { Patient characteristic }}$}

Subjects included patients admitted at the De La Salle University Medical Center from the period of January 1, 2010 to May 31, 2011 who underwent laparoscopic cholecystectomy as elective or emergency surgery (127 patients). Included in the study were patients of either sex between 16-80 years of age who underwent 4-port LC. Indication for surgery was symptomatic acute or chronic gallstone disease.

A written informed consent was obtained prior to surgery. Excluded in the study were patients who underwent Single-Incision Laparoscopic Surgery (SILS) and reduced port LC. 
Patients who had signs of biliary obstruction (Choledocholithiasis, cholangitis and Biliary Pancreatitis) were excluded in the study due to increased operative time, requirement of additional procedures such as Intraoperative Cholangiogram or Endoscopic Retrograde Cholangiopancreatography and prolonged hospital stay. All surgeries were done by consultants and assisted by another consultant and a resident as cameraman.

\section{Pre-Operative Management}

A written informed consent was secured with the explanation of the possibility of conversion to open cholecystectomy (OC) was done in all cases. Prophylactic antibiotics, the choice of the attending physician, was given one hour prior to induction of anesthesia.

\section{$\underline{\text { Operative Technique }}$}

A trans-umbilical incision was made thru the umbilical tube. A 10mm Hasson's trocar was then inserted, followed by carbon dioxide insufflation at $12 \mathrm{mmHg}$ with flow rate varying from 10-20 L/min. Three (3) $5 \mathrm{~mm}$ ports were inserted in the subxiphoid area, right upper quadrant and right lumbar area under direct visualization. Gallbladder was identified and dissection of the Calot's Triangle proceeded. Identification and isolation of the Cystic Artery and Cystic Duct ensued. Using the "critical view of safety" technique, 2 Hemoloc ${ }^{\circledR}$ clips were applied in the distal (patient) side of the artery and duct. Another clip was applied to the proximal (specimen) side prior to transection of the artery and duct. Gallbladder was then liberated from the gallbladder fossa. Adequate hemostasis of the gallbladder fossa was ensured. The gallbladder was then retrieved via a $10 \times 10 \mathrm{~cm}$ sterilized clear plastic bag, with a continuous suture (using Silk 1) $1 \mathrm{~cm}$ from the open edge (purse-string) secured using a Roeder's knot. The 
bag was inserted and retrieved thru the umbilical port. Port sites were infiltrated with $0.5 \%$ Bupivacaine prior to skin closure. Layer by layer closure of the umbilical incision was made to prevent incisional/umbilical hernia. The $5 \mathrm{~mm}$ ports were closed using interrupted, subdermal, monofilament sutures. Closed dressing (Tegaderm ${ }^{\circledR}$ on the umbilical incision and Opsite ${ }^{\circledR}$ on the $5 \mathrm{~mm}$ ports) were used.

\section{Post-operative Management}

Post-operative antibiotics were given at the discretion of the attending physician. Pain control consisted of 3 doses of intravenous analgesics followed by an oral analgesic taken as necessary.

Post-operatively, pain scale using the Visual Analog Scale was determined at 6,12 and 24 hours respectively. Operative time (from time of initial skin incision to the last stitch) was also noted as well as post-operative complications and the incidence of conversion to open cholecystectomy. Mean post-operative stay (emergence from anesthesia to discharge) was also measured.

\section{$\underline{\text { Statistics }}$}

Measures of central tendancy and frequencies of variables were analyzed using SPSS version 17 . 


\section{RESULTS}

There were 136 patients who underwent laparoscopic cholecystectomy from January 2010 to May 2011. Only 127 patients had a post-operative diagnosis of Chronic Calculous Cholecystitis (106 patients) and Acute Calculous Cholecystitis (21 patients). The others were excluded due to biliary obstruction which needed preoperative Endoscopic Retrograde Cholangiopancreatography (ERCP). Of the 127 patients, $115(90.6 \%)$ underwent 4-port LC, 11 (8.7\%) underwent 3-port LC and $1(0.8 \%)$ underwent single-port LC. Port number is surgeondependent. Majority of the surgeries were done using 4-port as described in Table 1.

Table 1. Number of patients who underwent 4-port LC, 3-port LC and SILS

\section{Number of Ports}

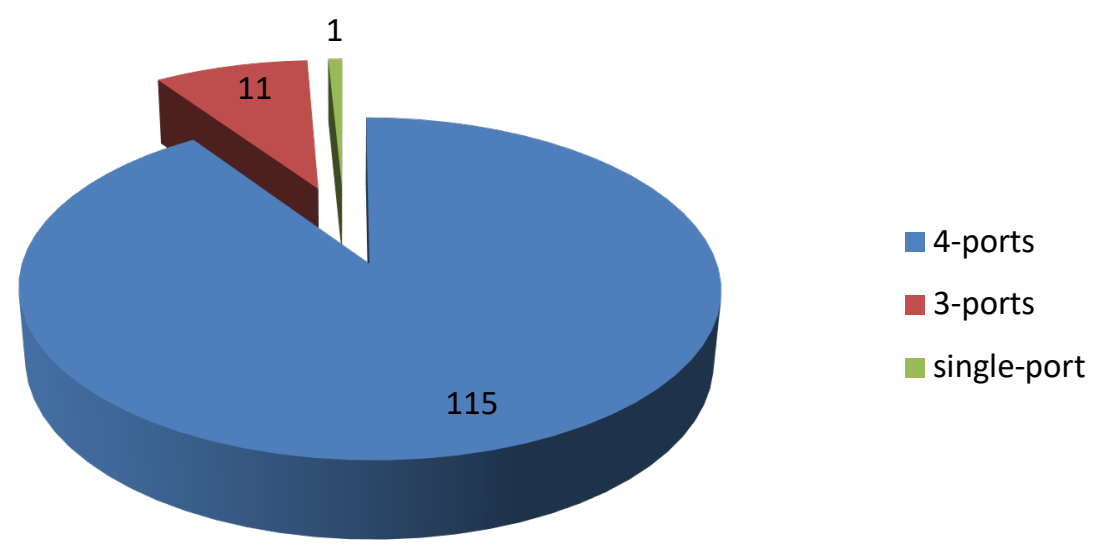


From the 115 patients who underwent 4-port LC, only $94(81.7 \%)$ were diagnosed to have Chronic Calculous Cholecystitis and 21 (18.3\%) were diagnosed to have Acute Calculous Cholecystitis, post-operatively.

During the 16-month period, intra-operative complications encountered during 4-port LC were 2 cases of excessive bleeding $(>100 \mathrm{cc})$ of the gallbladder $(\mathrm{GB})$ fossa $(1.7 \%), 2$ cases of cardiac arrhythmia (1.7\%), 2 cases of cystic artery bleed (1.7\%) and a cystic duct leak $(0.9 \%)$ due to excessive retraction that transected the cystic duct below the clips. Intra-operative Cholangiogram was done in 2 patients $(1.7 \%)$. Conversion to open cholecystectomy was done in 1 patient $(0.9 \%)$ due to difficulty in dissection of the triangle of Calot. Post-operatively, only 1 patient had a cystic duct leak due to released titanium clip which was managed with a closed suction drain and a post-LC ERCP Table 2 summarizes the number of patients with the complications stated above.

\begin{tabular}{|l|l|}
\hline COMPLICATIONS & PERCENT \\
\hline Excessive GB fossa Bleeding & $1.7 \%$ \\
\hline Cystic Artery Bleed & $1.7 \%$ \\
\hline Cardiac Arrhythmia & $1.7 \%$ \\
\hline Cystic Duct Leak & $0.9 \%$ \\
\hline Conversion & $0.9 \%$ \\
\hline None & $94.8 \%$ \\
\hline
\end{tabular}

Table 2. Intra operative complications of Laparoscopic Cholecytectomy in DLSUMC from January 2010 to May 2011. 
Pain scale was noted using the Visual Analog Scale for pain and was taken 6 hours, 12 hours and 24 hours post-operatively. A decrease in incision-site pain was noted at 24 hours postLC, as described in table 3 . All of these patients received $0.5 \%$ Bupivacaine infiltration prior to closure of the port sites. Also, majority of these patients had most pain experienced in the umbilical port-site.

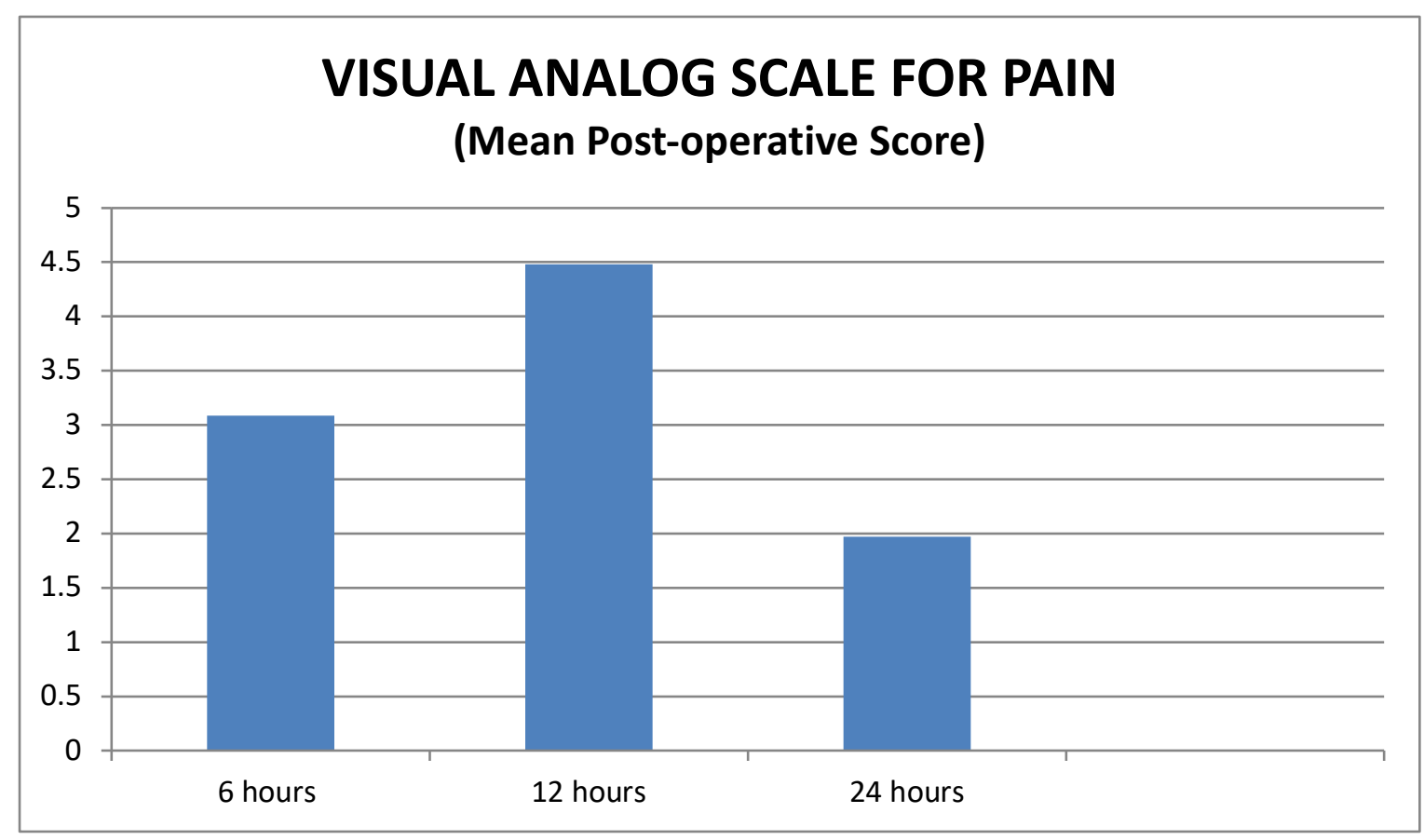

Table 3. VAS (Visual Analog Scale) for pain taken postoperatively at 6 hours, 12 hours and 24 hours.

In our institution, no post-LC mortalities occurred. The mean post operative stay after the procedure was $36.22(10-189 \mathrm{SD} \pm 25.01)$ hours. No wound infection nor early incisional hernia was noted after 1 week of follow up. 


\section{DISCUSSION}

Laparoscopic cholecystectomy has become the gold-standard for treatment of symptomatic cholecystitis. ${ }^{2,3,4}$ But due to its cost, some patients would rather opt for the open cholecytectomy to save money. In our institution, both open and laparoscopic cholecystectomy procedures are offered to the patient, either pay or service.

Laparoscopic cholecystectomy confers definite advantages compared to the open procedure, but carries its own risks. ${ }^{5}$ In our institution, only 6 patients had intraoperative complications(\%), occurred during the first few months when the surgeons were still less experienced. Post-operatively, only 1 complication was noted due to titanium clips which released from the transected cystic duct. This was rectified by a closed-suction drain placement and post-LC ERCP. Titanium clips were then replaced with Hemoloc ${ }^{\circledR}$ clips. No inadvertent release of clips noted since.

Bile duct injuries are a severe complication of laparoscopic cholecystectomy. Early recognition and multi-disciplinary approach will lead to the optimal outcome for the individual patient. ${ }^{8}$ In our institution, no bile duct injuries have occurred since the start of the study. The common complication we have encountered so far is bleeding on the gallbladder fossa $(1.7 \%)$ and inadvertent transection of the cystic artery prior to ligation (1.7\%). Both were recognized intraoperatively and was immediately rectified. Significant bleeding occurred in $0.5 \%$ of LC and is usually due to inadequate exposure, acute inflammation ${ }^{5}$.

In our institution, no post-LC mortalities occurred. The mean post operative stay after the procedure was $36.22(10-189 \mathrm{SD} \pm 25.01)$ hours. No wound infection nor early incisional hernia was noted after 1 week of follow up. 


\section{CONCLUSION}

With the early series of cases, it can be inferred that laparoscopic cholecystectomy is feasible and is performed safely in our institution. 


\section{$\underline{\text { References }}$}

1. P. Priego, C. Ramiro, J. M. Molina, G. Rodríguez Velasco, E. Lobo, J. Galindo and V. Fresneda. Results of laparoscopic cholecystectomy in a third-level university hospital after 17 years of experience. Rev esp enferm dig 2009; 101 (1): 20-30

2. A. Marinis, E. Stamatakis, A.Tsaroucha, N. Dafnios, G. Anastasopoulos, G. Polymeneas, T. Theodosopoulos. Safety and effectiveness of outpatient laparoscopic cholecystectomy in a teaching hospital: a prospective study of 110 consecutive patients. BMC Research Notes 2010, 3:207

3. J. Bueno Lledó, M. Planells Roig, C. Arnau Bertomeu1, A. Sanahuja Santafé, M. Oviedo Bravo, R. García Espinosa, R. Martí Obiol and A. Espí Salinas. Outpatient laparoscopic cholecystectomy. A new gold standard for cholecystectomy?. Rev esp enferm dig 2006; 98(1): 14-24

4. Chun Han Chau, Wing Tai Siu, Chung Ngai Tang, Ping Yiu Ha, Shek Yuen Kwok, Kwok Kay Yau, A. Chi Ngai Li and Michael Ka Wah Li. Laparoscopic Cholecystectomy for Acute Cholecystitis: The Evolving Trend in an Institution. Asian J Surg 2006;29(3):120-4]

5. K. Vagenas, S. Karamanakos, C. Spyropoulos, S. Panagiotopoulos, M. Karanikolas, M. Stavropoulos. Laparoscopic cholecystectomy: A report from a single center. World J Gastroenterol 2006 June 28; 12(24): 3887-3890

6. F. A. Habib, R. B. Kolachalam, R. Khilnani, O. Preventza, V. K. Mittal. Role of laparoscopic cholecystectomy in the management of gangrenous cholecystitis. The American Journal of Surgery 181 (2001) 71-75 
7. I.A. Shaikh, P. Sanjay, K. Joga, S. Yalamarthi, T. Daniel, A.I. Amin. Are we performing enough emergency laparoscopic cholecystectomies? An experience from a district general hospital. International Journal of Surgery 7 (2009) 482-484

8. E.A.J. Rauws, D. J. Gouma. Endoscopic and surgical management of bile duct injury after laparoscopic cholecystectomy. Best Practice \& Research Clinical Gastroenterology Vol. 18, No. 5, pp. 829-846, 2004. 